the Ituri forest hunting this scarce and extraordinary animal, and searching for the hypothetical Elephas pumilio ("Elephant nairn"), accompanied each day by one of my friends, the little Bambuti pigmies, without whose co-operation and assistance I could have done very little indeed. Elephants were everywhere, but not a sign of any pigmy species could I discover in the Ituri.

On several occasions I saw the okapi alive, sometimes at very close quarters, but so ghost-like, wary, and elusive is it, so difficult to track, even for the little "animal men," and so difficult is it to see in the prevailing gloom, that I only succeeded in shooting two. A third one (No. 53r) of the series was shot by Commandant Hedmark, an officer in the Congo service, who spent three days shooting with me at one of my forest camps, and came upon the animal quite by accident.

A fourth (No. 7I7) was killed, late one afternoon, in mistake for a buffalo, by Mr. A. E. H. Reid, a prospector, also in the Congo service, and given to me. This specimen is of considerable interest, being an old male with well-developed horns some 4 in. in length, and skin-covered except at the tip, where, instead of a tuft of hair, the bony horn-core is bare, somewhat cup-like in shape, and of modified, white, polished, very hard, compact bone. The remaining three skins were procured from natives and are very incomplete.

Hitherto there has been considerable confusion as to the sex to which the comparatively few skulls handled by naturalists belonged, and mainly for this reason there has been a doubt as to whether both sexes or only the male develops horns. There is no question as to the sex of four of my specimens, three males and one female. Two of the males have horns, but the third, being very immature, has not yet developed them. The big female, although an old animal, as shown by the condition of the teeth, has no horns or any signs of developing ossicones. This being so, I think I am justified in saying that my specimens go far towards proving that only the male okapi carries horns.

They also help to prove that the female okapi, unlike most other animals, attains a greater height and bulk than the male, a peculiarity suspected by a writer in Country Life (October 25, 1913) as the result of measurements of mounted specimens.

Giraffe-like as the animal seems, and is, it is only when extremely young that the backward slope of the back is very noticeable. It does not feed on any species of water-plant so far as I know. In fact, it seldom frequents low situations near the water. Its food consists of leaves of the undergrowth and young saplings, and in feeding it reaches to a considerable height, pulling down leafy twigs with its long prehensile tongue. It does not, I think, feed at night, but in the early evenings and the mornings until at least as late as nine or ten o'clock. 'It is not a jungleloving animal at all, but prefers the higher and drier parts of the forest, where the trees are big and the undergrowth comparatively scanty. It has no skulking bongo-like habits, but is never seen in the open. When going away at speed its neck is held straight in front, and it will jump obstacles rather than go beneath them, like the bongo and the little red buffalo.

Everything points to the okapi being the progenitor of the giraffe, or at least there seems little doubt that both are from the same stock. The okapi certainly does not appear to me to have any affinities with the antelopes.

Cuthbert Christy.

Royal Societies Club, St. James's Street, S.W., May 24.

\section{A Further Extension of the Spectrum.}

IN NATURE of May 7, I9I4 (vol. xciii., p. 24I), I stated that I had extended the ultra-violet limit of the spectrum to the neighbourhood of wave-length 900 Angström units.

I have now succeeded in carrying my observations to wave-length 600 . This result is chiefly due to the use of helium of considerable purity in my spectroscope and discharge tube. The apparatus is the same grating vacuum instrument which $\mathrm{I}$ have employed for several years, but perfected in such a way as to make it much more nearly air-tight than ever before. The spectrum which is obtained with a disruptive discharge in helium contains, between wavelength $125^{\circ}$ and 600 , upwards of fifteen lines, some of them of some strength.

My work with hydrogen confirms the existence of the series predicted by Ritz with members at 1216 , I026, and 972. But, owing to the great difficulty of obtaining the gas content of my spectroscope absolutely free from impurities, I am not even yet able to identify positively the source of certain strong lines which occupy the positions demanded by the analogue of the Pickering series, and occur both when hydrogen and when helium are employed.

$$
\begin{gathered}
\text { The Iefferson Laboratory, Harvard University, } \\
\text { May II. }
\end{gathered}
$$

The Distribution of the Electrons in Atoms.

THE spectra which are obtained by the diffraction of X-rays by crystals are characteristic both of the substance which emits the X-rays and of the crystal which acts as the grating. If the lines of an accurately ruled plane grating are small in width compared with their distance apart, the intensities of the different orders of spectra are nearly the same. If, however, the lines have a width comparable with the grating constant, the intensities of the higher orders rapidly diminish. When a crystal diffracts a beam of $\mathrm{X}$-rays, the different layers of atoms correspond to the lines of the ordinary transmission grating, so that the relative intensity of the higher orders of spectra will depend upon the ratio of the effective diameter of the atoms in scattering the X-rays to the distance between the successive layers of atoms.

There are good reasons for believing that it is the electrons in atoms which scatter the X-rays. On this assumption it may be shown that if the density of the space distribution of the electrons in each layer of atoms is some function $f(z)$ of $z$, where the $z$ axis is taken normal to the reflecting planes, the ratio of the amplitude of the $n$th order spectrum to the amplitude it would have if all the electrons were in the same plane is :-

$$
\frac{\mathrm{P}}{\mathrm{P}_{0}}=\frac{\int_{a}^{b} f(z) \cos (\beta+2 \pi n z / d) d z}{\cos \left(\beta+\pi n \frac{b+a}{d}\right) \int_{a}^{b} f(z) d z},
$$

where $b-a=d$ is the grating space, and $\beta$ is the - phase angle of the reflected ray. If it is possible to find some function $f(z)$ which will lead to the values of $\mathrm{P} / \mathrm{P}_{0}$ as determined experimentally, an indication will be obtained of the distribution of the electrons in the atoms.

W. H. Bragg has published experimental results (Phil. Mag., vol. xxvii., p. 895, I9I4) showing the rate of variation of the intensity with the order when $\mathrm{X}$-rays are reflected from rock-salt. It can be shown from his data that the intensities of the different

No. 2378 , vol. 95] 